\title{
Investigation of the overall transient performance of the industrial two-phase closed loop thermosyphon
}

\author{
CHARLES C. J. VINCENT $†$ and JIM B. W. KOK $\$$ \\ Department of Thermal Engineering, University of Twente, \\ P.O. Box 217, 7500 AE, Enschede, The Netherlands
}

(Received 17 September 1990 and in final form 4 June 1991)

\begin{abstract}
The two-phase closed loop thermosyphon is investigated with emphasis on the overall performance in transient operation. The control volume approach is the base of a global analysis describing the motion of vapor and liquid phases of the thermosyphon system in one-dimensional equations. Interfacial shear forces are neglected as only co-current flows are present. Heat transfer coefficients are based on empirical correlations. It is found that the density ratio vapor-liquid, dimensionless friction coefficient and water column length determine respectively the overall dynamic behavior characteristics such as response time, damping and oscillation frequency.
\end{abstract}

\section{INTRODUCTION}

A THERMOSYPHON is a heat transfer device of very high thermal conductance in which fluid circulates. The heat transfer is considered to be affected by many factors, such as working fluid, quantity of the working fluid, inside pipe diameter, pipe length, ratio of cooled surface to heated surface, adiabatic length between heated and cooled sections, heat flux and operating temperature. Thermosyphons are found in many applications: gas turbine-blade cooling [1], thermal stabilization [2], air-to-air or gas-to-gas heat exchangers [3], prevention of icing on a buoy [4], utilization of hot water [5] and for recovering waste heat in industrial fields [6].

In recent years, many studies have been carried out on the heat transfer in different types of thermosyphons. Research on counter-current two-phase closed thermosyphons was first performed by Cohen and Bayley [1] in 1955, followed by, among others, Strel'tsov [7] and more recently by Dobran [8] and Reed [9]. Torodial thermosyphons were investigated by Hart [10] and Sen et al. [11]. Huang and Zelaya [12] and Zvirin [13] have analyzed rectangular closed loop-phase thermosyphons.

In industrial applications, there is a preference for co-current two-phase thermosyphons because of : (1) their capability of transporting large heat quantities at very small temperature differences, (2) less liquidvapor interaction and (3) no limitations like dry-out phenomena. Early models of co-current two-phase

† Present address: Shell Pcrnis, P.O. Box 70003000 HA, Rotterdam, The Netherlands.

† To whom correspondence should be addressed. thermosyphons by Hughmark [14] and Flair [15] were not based on first principles. Research on two-phase co-current thermosyphons concerning heat transfer coefficients was conducted by Hallinan and Viskanta [16]. McDonald et al. [17-20] studied the thermal conductance of a two-phase thermosyphon in steadystate operation. Leidenfrost and Modrei [21] investigated, experimentally, heat transfer and flow conditions in the two-phase co-current thermosyphon.

In this paper, a model is presented which describes the transient operation of a co-current two-phase thermosyphon. A control volume approach, also used by Dobran [8] and Reed [9], is applied. The working liquid is water. The transient behavior of the thermosyphon will be investigated at three different operating temperatures. The thermosyphon is analyzed with emphasis on the dynamic behavior of evaporator and condensor temperature, water and vapor mass fluxes in transient operation. Three dynamic system characteristics have been investigated : damping, free oscillation period and response time.

Furthermore, a practical case is simulated. This practical case was derived from the application of a two-phase thermosyphon for the batchwise heating of vegetable oil. In a batch process trays of cold oil are heated by the condensor of a thermosyphon to a specified temperature. In this process the evaporator temperature is controlled by switching the heat source (a boiler) on/off. Due to this batchwise heating and the unsteady heat source the thermosyphon is operated under essentially unsteady conditions and the dynamics of temperatures and mass fluxes become important for efficient and reliable operation. Problems that may occur are, for example, large transient water fluxes or water flow reversal. These phenomena may damage 


\section{NOMENCLATURE}

c specific heat $\left[\mathrm{Jg}{ }^{\prime} \mathrm{K} \cdots '\right]$

d tubo diameter [m]

f. Iriction coefficient

$F$ coefficient

$g \quad$ acceleration of gravity [m s $\left.{ }^{-2}\right]$

$h$ heat transfer coefficient [W $\left.\mathrm{m}^{-2} \mathrm{~K}^{-1}\right]$

$H$ 、 latent heat of condensation $\left[\mathrm{J} \mathrm{kg}^{-1}\right]$

$H$ height [m]

$L, l$ length $[\mathrm{m}]$

$M$ total mass $[\mathrm{kg}]$

$N$ number

$P \quad$ pressure $\left[\mathrm{Nm}^{-3}\right]$

$Q$ heat, power [Js ']

$r$ tube radius $[\mathrm{m}]$

Re Reynolds number

$s \quad$ loop coordinate [m]

$t$ time [s]

$T$ temperature $[\mathrm{K}]$

$V \quad$ velocity $\left[\mathrm{m} \mathrm{s}^{-1}\right]$.
Greek symbols

i film thickness [m]

i thermal conductivity $\left[\mathrm{Wm} \mathrm{m}^{\prime} \mathrm{K} \cdot{ }^{1}\right]$

it dynamic viscosity $\left[\mathrm{kgm}^{\prime} \mathrm{s}\right]$

$\rho$ density $\left[\mathrm{kg} \mathrm{m}^{*}{ }^{i}\right]$.

\section{Subscripts}

$\begin{array}{ll}\text { c } & \text { condensor } \\ \text { e } & \text { cvaporator } \\ \text { h } & \text { horizontal } \\ \text { i } & \text { interphase } \\ \text { l } & \text { liquid } \\ \text { n } & \text { nominal } \\ \text { p } & \text { phase } \\ \text { r } & \text { reference } \\ s & \text { loop section } \\ \text { v } & \text { vapor, vertical. }\end{array}$

the thermosyphon or cause it to malfunction. Therefore it is important to simulate these situations and to investigate how to avoid them.

\section{PHYSICAL MODEL}

Although there are different types of closed loop thermosyphons, a general layout is depicted schematically in Figs. 1(a) and (b). Liquid and vapor are transported through a system of pipes (Fig. 1(a)). In the condensor, the vapor flow is divided over several heat coils. The evaporator consists of an assembly of vertical pipes (Fig. 1(b)). As the total cross-section of the evaporator is larger than that of the condensor, a small change of water elevation in the evapor- ator causes a large change of water elevation in the condensor.

Common industrial conditions are high operating temperatures, up to $280^{\circ} \mathrm{C}$, water as working liquid, power supply of 1-2 MW and a liquid filling of 0.3 $1 \mathrm{~m}^{3}$. The evaporator pipes are flooded to prevent local overhcating. The heat source is a boiler, the heat sink a tray of liquid, for example vegetable oil. The oil is heated to a certain temperature and then removed. The boiler shuts off, a new batch of oil enters the tray and the boiler is set on firing again. Temperature differences over the vapor pipe and the condensate pipe are caused by heat losses. As thermosyphons are well insulated and heat losses are small, the system can be described by two characteristic temperatures, namely the evaporator and condensor temperatures. This was verified by temperature measure-

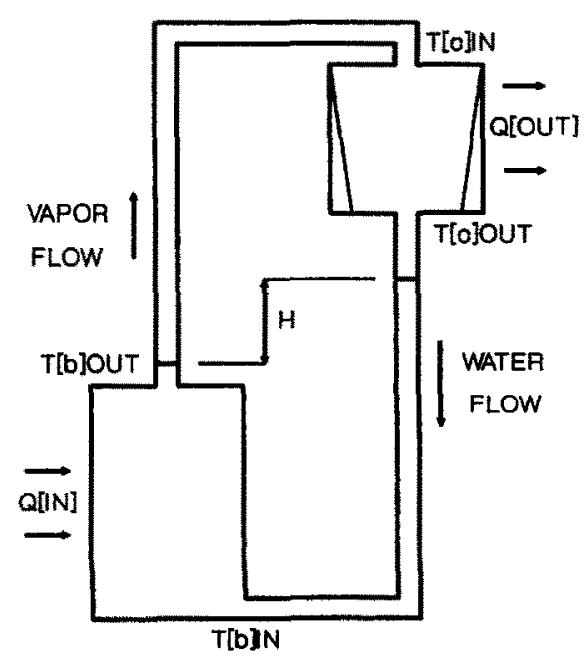

FIG. I(a). Idealized closed loop thermosyphon.

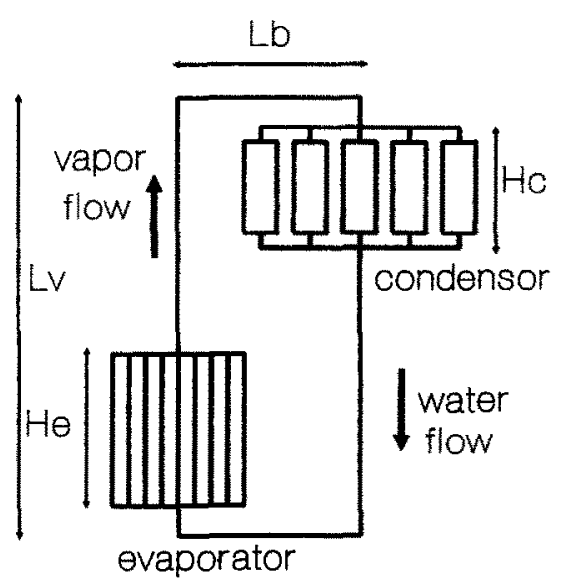

FiG. I (b). Thermosyphon piping layout. 


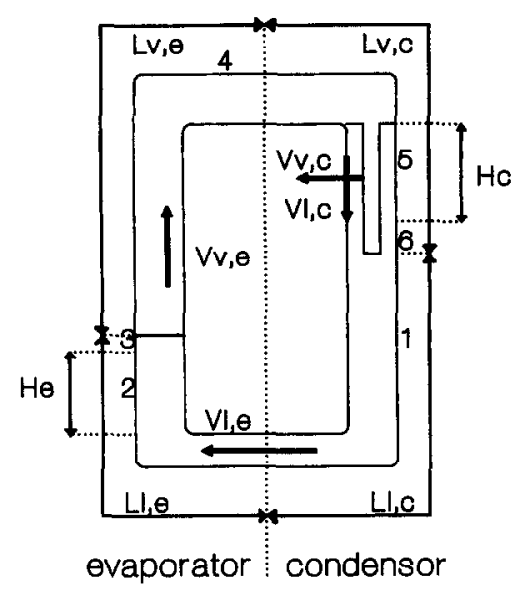

Fig. 2. Schematic model of the thermosyphon.

ments at three full scale industrial thermosyphons carried out by Vincent [22].

In the present study, the thermosyphon is divided into two control volumes (see Fig. 2). One control volume contains the liquid and vapor phase of the evaporator region and the second control volume includes the liquid phase (consisting of the liquid pool and the liquid film) and vapor phase of the condensor region. A one-dimensional model has been developed, simulating parallel pipes by one long serial pipe with nominal diameter $d_{n}$. The model accounts for differences in lengths and cross-sections of the different loop components. It is assumed that the vapor is saturated in both evaporator and condensor sections. The solution is facilitated by the neglection of the phenomena caused by the heat capacity of the piping, heat losses, axial conduction and viscous dissipation. The film thickness is thought of as negligibly small compared to the tube radius. The dynamic viscosity and the spccific heat arc assumed to have constant values. The present analysis is based on a control volume formulation of the mass, energy, volume and momentum macroscopic balances according to Bird et al. [23].

The evaporator region is governed by equations (1)-(3) below. Mass balances of liquid and vapor phases are, respectively:

$$
\begin{gathered}
\pi r^{2} \frac{\mathrm{d}}{\mathrm{d} t}\left[\rho_{\mathrm{le}} l_{\mathrm{le}}\right]=\pi r^{2}\left(\rho_{\mathrm{lc}} v_{\mathrm{le}}-\rho_{\mathrm{ve}} v_{\mathrm{ve} . \mathrm{j}}\right) \\
\pi r^{2} \frac{\mathrm{d}}{\mathrm{d} t}\left[\rho_{\mathrm{ve}} l_{\mathrm{ve}}\right]=\pi r^{2} \rho_{\mathrm{ve}}\left(v_{\mathrm{ve} . \mathrm{i}}-v_{\mathrm{ve}}\right)
\end{gathered}
$$

If the temperatures of the liquid and vapor flow are identical, the energy exchange with the ambient should equal the energy for phase change. Therefore, a system temperature is defined, equal to the mean temperature of evaporator and condensor section: $T_{\mathrm{r}}=0.5\left(T_{\mathrm{c}}+T_{\mathrm{c}}\right)$. As the vapor is assumed to be saturated, the two separate phase energy balances can be replaced by one total energy balance :

$$
\begin{aligned}
& \pi r^{2} \frac{\mathrm{d}}{\mathrm{d} t}\left[\rho_{\mathrm{le}} l_{\mathrm{le}} c_{1}\left(T_{\mathrm{e}}-T_{\mathrm{r}}\right)\right. \\
& \left.+\rho_{\mathrm{ve}} l_{\mathrm{ve}} c_{\mathrm{v}}\left(T_{\mathrm{e}}-T_{\mathrm{r}}\right)\right]=\pi r^{2}\left(\rho_{\mathrm{lc}} v_{\mathrm{lc}} c_{\mathrm{g}}\left(T_{\mathrm{c}}-T_{\mathrm{r}}\right)\right. \\
& \left.\quad-\rho_{\mathrm{ve}} v_{\mathrm{ve}, \mathrm{i}}\left(c_{\mathrm{v}}\left(T_{\mathrm{e}}-T_{\mathrm{r}}\right)+H_{\mathrm{v}}\right)\right)+Q_{\mathrm{in}} .
\end{aligned}
$$

The condensor rcgion is governed by equations (4)(7) below. Mass balances of the liquid pool and vapor core are, respectively:

$$
\begin{gathered}
\pi r^{2} \frac{\mathrm{d}}{\mathrm{d} t}\left[\rho_{\mathrm{lc}} l_{\mathrm{lc}}\right]=2 \pi r \delta \rho_{\mathrm{lc}} v_{\mathrm{lc}}-\pi r^{2} \rho_{\mathrm{lc}} v_{\mathrm{le}} \\
\pi r^{2} \frac{\mathrm{d}}{\mathrm{d} t}\left[\rho_{\mathrm{vc}} l_{\mathrm{vc}}\right]=\pi r^{2} \rho_{\mathrm{ve}} v_{\mathrm{ve}}-2 \pi r l_{\mathrm{c}} \rho_{\mathrm{vc}} v_{\mathrm{vc}, \mathrm{i}}
\end{gathered}
$$

The liquid film has uniform thickness. The rate of growth of liquid film thickness is determined by the balance of the mass rate of condensing vapor and the mass rate of flowing liquid:

$$
2 \pi r \frac{\mathrm{d}}{\mathrm{d} t}\left[\rho_{\mathrm{lc}}\left(l_{\mathrm{vc}}-0.5 l_{\mathrm{h}}\right) \delta\right]=2 \pi r l_{\mathrm{c}} \rho_{\mathrm{vc}} v_{\mathrm{vc}, \mathrm{i}}-2 \pi r \delta \rho_{\mathrm{lc}} v_{\mathrm{lc}} .
$$

As the vapor phase is saturated, there is one energy balance:

$$
\begin{aligned}
& \frac{\mathrm{d}}{\mathrm{d} t}\left[\pi r^{2} \rho_{\mathrm{vc}} l_{\mathrm{vc}} c_{\mathrm{v}}\left(T_{\mathrm{c}}-T_{\mathrm{r}}\right)+2 \pi r \delta \rho_{\mathrm{lc}}\left(l_{\mathrm{vc}}-0.5 l_{\mathrm{h}}\right) c_{1}\left(T_{\mathrm{c}}-T_{\mathrm{r}}\right)\right. \\
& \left.\quad+\pi r^{2} \rho_{\mathrm{lc}} l_{\mathrm{cc}} c_{1}\left(T_{\mathrm{c}}-T_{\mathrm{r}}\right)\right]=2 \pi r l_{\mathrm{c}} \rho_{\mathrm{vc}} v_{\mathrm{vc} . \mathrm{i}} H_{\mathrm{v}} \\
& \quad+\pi r^{2}\left(\rho_{\mathrm{ve}} v_{\mathrm{vc}} c_{\mathrm{v}}\left(T_{\mathrm{c}}-T_{\mathrm{r}}\right)-\rho_{\mathrm{lc}} v_{\mathrm{lc}} c_{\mathrm{l}}\left(T_{\mathrm{c}}-T_{\mathrm{r}}\right)\right) \\
& \quad-2 \pi r l_{\mathrm{c}} h\left(T_{\mathrm{c}}-T_{\mathrm{oil}}\right)
\end{aligned}
$$

The momentum balance between the evaporator and condensor regions of the liquid phase is :

$$
\begin{aligned}
\frac{\mathrm{d}}{\mathrm{d} t}\left[\sum_{s=1}^{3}\left\{l_{\mathrm{ls}} \rho_{\mathrm{ls}} v_{1}\right\}\right]=P_{\mathrm{c}}-P_{\mathrm{c}} \\
\quad-\sum_{s=1}^{3}\left\{\frac{f_{\mathrm{l}} l_{\mathrm{l} s}}{N_{s} d_{s}} 0.5 \rho_{\mathrm{ls}}\left(\frac{d_{\mathrm{n}}^{2}}{N_{s} d_{s}^{2}} v_{1}\right)^{2}\right\}+g\left(\rho_{\mathrm{lc}} H_{\mathrm{lc}}-\rho_{\mathrm{lc}} H_{\mathrm{lc}}\right)
\end{aligned}
$$

and that of the vapor phase, neglecting the static vapor head, is :

$$
\begin{aligned}
\frac{\mathrm{d}}{\mathrm{d} t}\left[\sum_{s=4}^{6}\left\{l_{\mathrm{vs}} \rho_{\mathrm{ve}} v_{\mathrm{v}}\right\}\right] & =P_{\mathrm{e}}-P_{\mathrm{c}} \\
& -\sum_{s=4}^{6}\left\{\frac{f_{\mathrm{v}} l_{\mathrm{vs}}}{N_{s} d_{s}} 0.5 \rho_{\mathrm{vs}}\left(\frac{d_{\mathrm{n}}^{2}}{N_{s} d_{s}^{2}} v_{\mathrm{v}}\right)^{2}\right\} .
\end{aligned}
$$

The batch of oil is assumed to be insulated, hence the heat transport from condensor to oil is described by:

$$
\frac{\mathrm{d}}{\mathrm{d} t}\left[M_{\text {oil }} c_{\text {oil }} T_{\text {oil }}\right]=2 \pi r l_{\mathrm{c}} h\left(T_{\mathrm{c}}-T_{\text {oil }}\right)
$$

The volume balances express that the volumes of evaporator and condensor sections remain constant :

$$
l_{\mathrm{ve}}+l_{\mathrm{le}}=L_{\mathrm{e}} \text { and } l_{\mathrm{vc}}+l_{\mathrm{lc}}=L_{\mathrm{c}} .
$$


In co-current flows, the impact of interfacial shear stress is much less than in counter-current flows, hence the liquid flow velocity can be based on Nusselt's theory, neglecting interfacial shear stress, for a flat plate:

$$
v_{\mathrm{kc}}=\frac{g \rho_{\mathrm{k}} \delta^{2}}{3 \mu_{1}}
$$

Eight auxiliary algebraic equations close the set of equations (1)-(12): the thermodynamical relationships between density, pressure and temperature in saturated liquid-vapor mixtures, three equations for each section (see Vincent [22]), and the relationships between water elevations, $H_{\mathrm{le}}$ and $H_{\mathrm{lc}}$, and water column lengths, $l_{\mathrm{e}}$ and $l_{\mathrm{c}}$.

The heat transfer coefficient, based on empirical and experimental data, has the value $8.5 \times 10^{3} \mathrm{~W} \mathrm{~m}^{-2}$ $\mathrm{K}^{-1}$ [22]. The friction coefficient $f$ is based on the Blasius correlation for turbulent flow in smooth pipes: $f=0.3164 / R e^{1 / 4}[23]$. As the Reynolds number in the model calculations is high for water flow of about $10^{4}$ and vapor flow of about $10^{5}$, the friction coefficients can be assumed to be constant: 0.03 for water and 0.02 for vapor flow

\section{INITIAL CONDITIONS}

Our goal is to analyze the transient behavior of a two-phase thermosyphon. The simulation of transient opcration starts by perturbing a thermosyphon initially in equilibrium, i.e. in steady-state operation. Therefore the steady-state conditions have to be calculated because they are needed to serve as initial conditions for the simulation of transient operation.

In steady-state operation, all time derivatives vanish. Equations (1)-(10) simplify to algebraic equations and can be rewritten as follows. In the steadystate the two energy equations (7) and (8) become identical. This leaves us with one more unknown than we have equations. As a consequence the system becomes indeterminate: one variable is free to be chosen as a parameter. As the temperature determines three variables, namely pressure, water and steam density, the evaporator section temperature is the selected parameter to determine the system. The remaining variables are solved numerically from the system of nonlinear algebraic equations. This way the initial conditions necessary for the transient analysis are obtained.

The dependence of the equilibrium values on process parameters, like for example the tube radius, will not be discussed here. There is a considerable amount of literature on the dependence of steady-state heat transfer in a two-phase closed loop thermosyphon on process parameters. For example, McDonald et al. [17-20] performed numerical simulations as well as experimental research on the steady-state performance characteristics of two-phase co-current thermosyphon loops. McDonald and co-workers investigated thoroughly the dependence of the thermal conductance on loop filling, angle of inclination of evaporator and condensor tubes, temperature difference, etc. More references on steady-state performance of two-phase thermosyphons can be found in a review on natural circulation loops by Greil [24].

\section{TRANSIENT ANALYSIS}

The transient behavior of the system after a perturbation of the system in steady-state operation is computed. The solution of the transient system starts with the integration of the differential equations (1) (10) with a time step of $0.01 \mathrm{~s}$, using the conventional Euler method. Then the other parameters in the algebraic equations are updated and the new values of the section temperatures of the next time step are determined. This process is continued until the final time step is reached. The solution procedure is documented in detail elsewhere [22].

\section{Response time}

The system response after a step in heat input is investigated. A positive step in heat input causes a quick response in pressure drop over the steam pipe between evaporator and condensor sections. To compensate this, the water head in the condensate pipe should increase. The time delay between this increase and the step in heat input is larger via the steam side, because of heating delay in the condensor and the longer intermediate distance, than via the water side. Hence, the increase in water head is at first achieved by a decrease in returned condensate flow (to the evaporator)

From conservation of mass it follows that a small vapor-liquid density ratio corresponds to a large vapor-liquid velocity ratio. In equation (9) we see that at high vapor velocities, an increase in this velocity causes a large increase in pressure drop and. hence, a long time to re-establish steady-state conditions. This way it can be reasoned that the vaporliquid density ratio will determine the transient evolution of the system

Responses of the system are investigated by a rise in heat input of $30 \%$ in $\Delta t=0.5 \mathrm{~s}$, under the initial operating conditions: evaporator temperature $T=$ $90 \mathrm{C}$ with heat input $Q=0.2 \mathrm{MW}$, and $T=170 \mathrm{C}$. $T=250^{\circ} \mathrm{C}$ with $Q=1 \mathrm{MW}$.

The calculations described below were performed with model dimensions given in Table 1.

The time response of the system is analyzed from the time response of the evaporator vapor flow and the

Table 1. Model dimensions

$l_{\mathrm{l}}=5 \mathrm{~m} \quad d_{\mathrm{e}}=30 \mathrm{~mm} \quad H_{\mathrm{e}}=3 \mathrm{~m} \quad N_{\mathrm{c}}=4$

$l_{\mathrm{v}}=15 \mathrm{ml} \quad d_{\mathrm{c}}=40 \mathrm{~mm} \quad H_{\mathrm{c}}=2 \mathrm{~m} \quad M_{\text {waler }}-375 \mathrm{~kg}$

$l_{\mathrm{c}}=20 \mathrm{~m} \quad d_{\mathrm{n}}=50 \mathrm{~mm} \quad N_{\mathrm{c}}=200 \quad M_{\text {oil }}=4.5 \times 10^{3} \mathrm{~kg}$ 


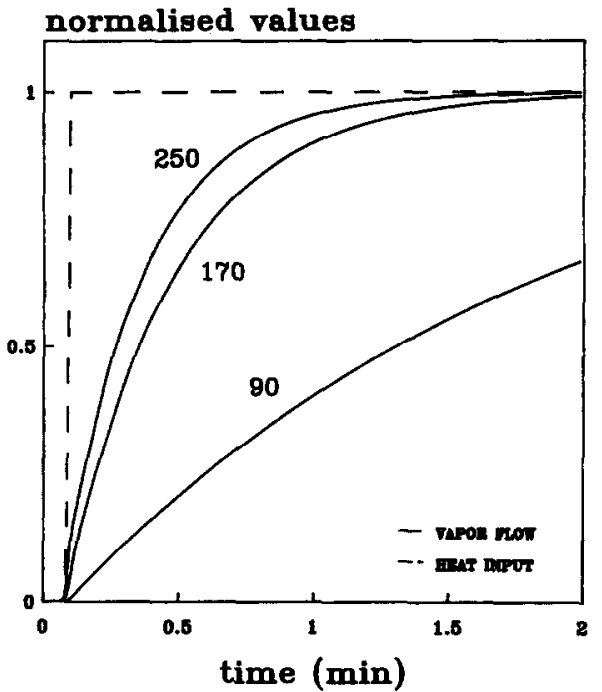

Fig. 3. Evaporator flow responses at $T=90^{\circ} \mathrm{C}, T=170^{\circ} \mathrm{C}$ and $T=250^{\circ} \mathrm{C}$.

evaporator water flow. Figure 3 shows the evaporator vapor flow response (normalized by the final value) for three evaporator temperatures: $90^{\circ} \mathrm{C}, 170^{\circ} \mathrm{C}$ and $250^{\circ} \mathrm{C}$. The normalized heat input as a function of time is also shown. We see that the higher the evaporator temperature, the faster the vapor flow response will be.

In Fig. 4 the time response of the evaporator water flow is shown for two operating tempcraturcs : $250^{\circ} \mathrm{C}$ and $170^{\circ} \mathrm{C}$. As with the vapor flow the time response of the water flow is much faster at $250^{\circ} \mathrm{C}$ than at $170^{\circ} \mathrm{C}$. To show that this is actually due to an increased vapor-liquid density ratio, a third simulation is shown (marked $170 \rho$ ). This was performed at an operating temperature of $170^{\circ} \mathrm{C}$ but with an arti-

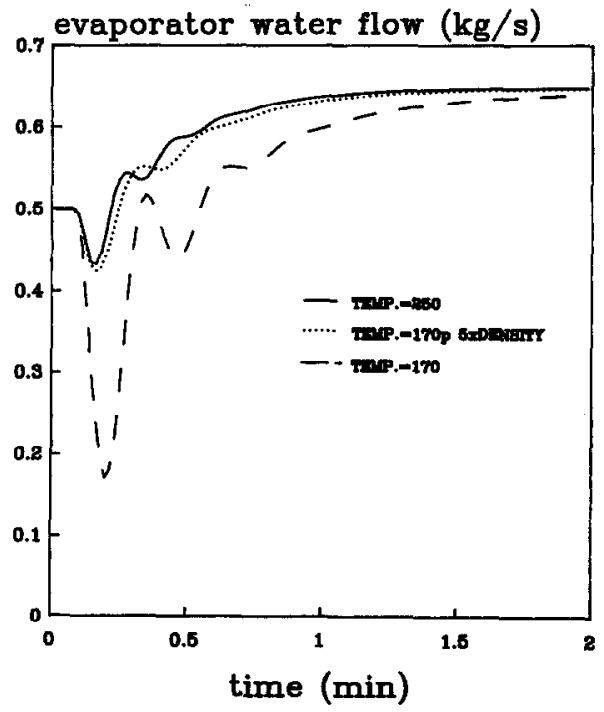

FiG. 4. Evaporator water flow responses at $T=250^{\circ} \mathrm{C}$, $T=170^{\circ} \mathrm{C}$ and $T=170^{\circ} \mathrm{C}$, with artificially high vaporliquid density ratio. ficial five times larger vapor-liquid density ratio. We see that the curves of $250^{\circ} \mathrm{C}$ and $170 \rho$ are almost identical. Thus we can conclude that the larger the vapor-liquid density ratio of the system's fluid (for example, due to high operating temperatures), the faster the system will respond. As found in countercurrent thermosyphons [9], the responses in closed loop thermosyphons are lead by vapor flow.

\section{Damping}

Analyzing the system of equations (1)-(12), it is seen that the momentum equations (8) and (9) are sensitive to input changes. Flow variations have to be damped by friction. As the value of the energy dissipation term $\left(f_{\mathrm{p}} l_{\mathrm{p}} / d\right) 0.5 \rho_{\mathrm{p}} v_{\mathrm{p}}^{2}$ in the vapor momentum equation (9) is large compared to the term in the water momentum equation (8), the condensate flow is much more sensitive to changes in operating conditions than the vapor flow. The oscillation of the condensate flow induces oscillations in other variables such as the water head.

In Fig. 5 the responses of the evaporator water flow on a temporary rise in heat input of $20 \%$ at evaporator temperature $T=170^{\circ} \mathrm{C}$ and heat input $Q=1 \mathrm{MW}$ during $\Delta t=0.5 \mathrm{~s}$ are shown for three different water friction factors. To show the responses separately, one response $\left(f_{1}=0.09\right)$ is moved a $\Delta y=0.03 \mathrm{~kg} \mathrm{~s}^{-1}$ upwards and one response $\left(f_{1}=0.015\right)$ to a $\Delta y=0.03$ $\mathrm{kg} \mathrm{s}^{-1}$ downwards. We see that at the low friction factor $f_{1}=0.015$ the evaporator water flow can make many oscillations after a perturbation. Increasing the friction factor to 0.03 , the number of oscillations is decreased. For $f_{1}=0.09$, an optimally damped situation is created. This value is, however, too high to be achieved by surface roughness but the pressure drop can also be obtained by obstructing the water flow through a certain part of the condensate piping.

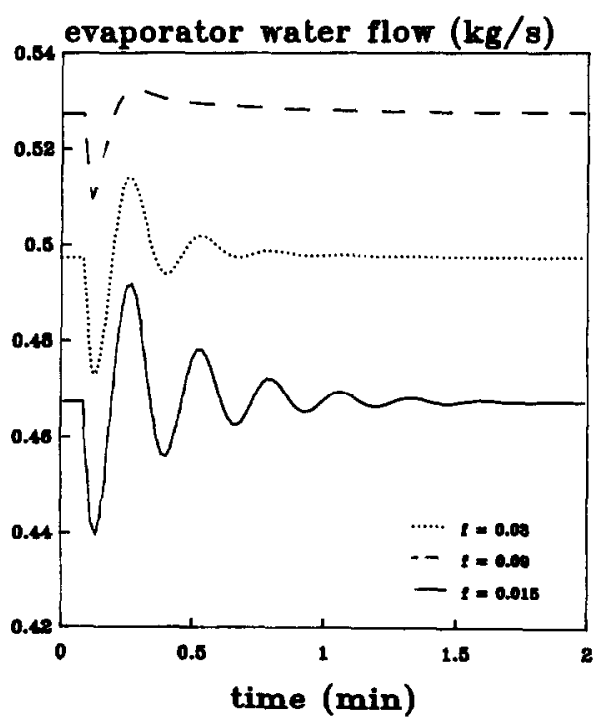

Fig. 5. Evaporator water flow responses at three different water friction coefficients. 
Period of free oscillation

The dynamics of the water flow in the thermosyphon system show some analogy with a water-filled open U-tube. The period of free oscillation of a water column with length $L$ oscillating under gravitational acceleration $g$ in an open $U$-tube with equal pressure at both legs is [23]

$$
\text { oscillation period }=2 \pi \sqrt{ }(L / 2 g) .
$$

It is hard to calculate analytically the free oscillation period of the water flow in a thermosyphon from cquations (1)-(12). For this reason the free oscillation period of the water flow of a closed loop thermosyphon is deduced from the simulated time response after a stepwise perturbation. As we want to read the oscillation period from the time response the damping has to be set low. Therefore we set the energy dissipation in the condensate pipe to zero by putting the water friction coefficient equal to zero. The vapor friction coefficient is made small but cannot be set 10 zero as this would also set the pressure difference between the boiler and condensor section to zero. Hence there still remains a small amount of energy dissipation and the pressures in both sections are not identical. It is clear that the system cannot exactly be compared with the U-tube system. However, it is expected that an equation analogous to (13a) determines the free oscillation period of the thermosyphon system. Hence

$$
\text { oscillation period }=F 2 \pi \cdot \sqrt{ }(I / 2 g)
$$

in which $F$ is a lumped coefficient.

Figure 6 shows the evaporator water flow oscillations at evaporator temperature $T=170 \mathrm{C}$, heat input $Q=1 \mathrm{MW}$ and at two water column lengths, as responses on a rise in heat input of $20 \%$ during $\Delta t=0.5 \mathrm{~s}$. It is noted that because of the energy
Table 2. Coefficient $F$ as a function of temperature

$\begin{array}{llllllll}T(C) & 90 & 130 & 170 & 210 & 235 & 247 & 30 \\ F & 1.41 & 1.43 & 1.46 & 1.44 & 1.30 & 1.28 & 11\end{array}$

dissipation in the steam pipe. the oscillation is slightly damped. We see that a four times larger $l$. causes an exact, less than $1 \%$ deviating. doubling of the oscillation frequency, confirming that the $L$ in equation (13b) is in the square root form. This was verified at several other temperatures from 90 ( ) to 250$)($.

The dependence of coefficient $F$ on temperature is shown in Table 2. It is found that the coefficient $F$ is about 1.4 at lower temperatures and approaches unity for higher temperatures. This can be explained by the fact that for higher temperatures the pressure difference decreases and thus the thermosyphon system resembles more an open U-tubc. These results are in agreement with the experimental results of Leidenfrost and Modrei [21]. They made measurements on flow oscillations with refrigerant fluid R-1i at low pressure

\section{Pratical tase simulation}

Three practical cases are simulated to determine the effect of time delay between a change in heat input and heat output, namely via boiler start up and drop in temperature of the heat sink, provided by the batch of oil. Figurc 7 shows the temperatures of the evaporator section in each case and the oil temperature. In all cases the boiler heat input is set to zcro at $t=1 \mathrm{~min}$. As a consequence the water temperature decreases to the oil temperature between $t=1 \mathrm{~min}$ and $t=2 \mathrm{~min}$. Subsequently the temperature of the batch of oil drops at $t=2 \min$ from $240^{\circ} \mathrm{C}$ to $170 \mathrm{C}$ in $2 \mathrm{~min}$ and the heat input of the boiler increases linearly from 0

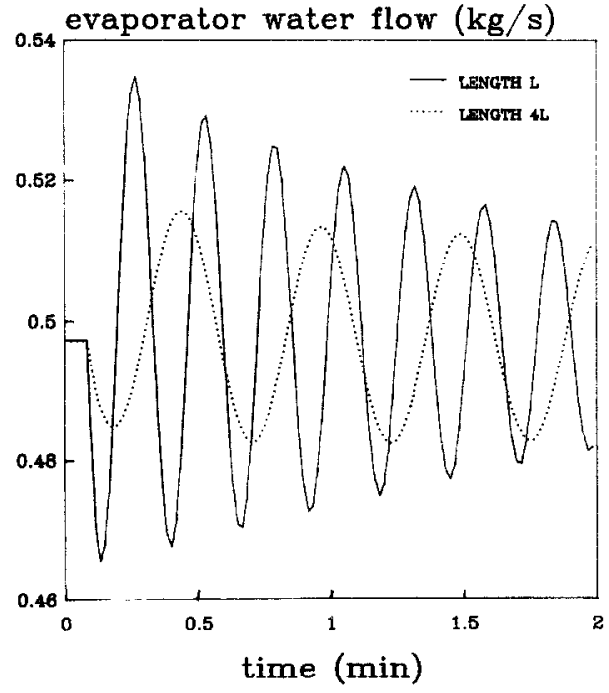

FiG. 6. Evaporator water flow responses at $T=170^{\circ} \mathrm{C}$ and low damping. temperature (C)

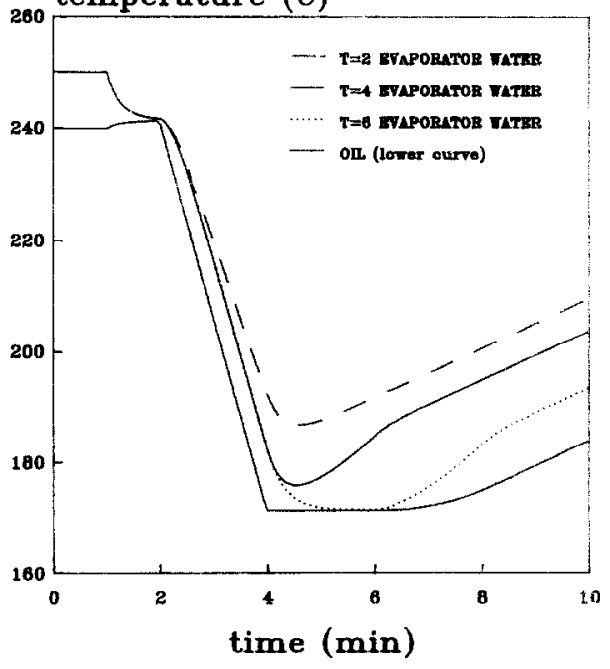

Fig. 7. Temperatures of evaporator section and of oil after drop of a new batch of oil. 
to $1 \mathrm{MW}$ in $2 \mathrm{~min}$. The time of boiler start up is varied for three different times : $t=2, t=4$ and $t=6 \mathrm{~min}$.

In Fig. 7 we see that an increase in time delay of boiler start up shifts the evaporator water temperature curve to the right, to longer times. The nature of the temperature response is, however, unchanged, and so is the slope of the temperature curve after $t=8 \mathrm{~min}$. It is interesting that at the time delays used here there is no visible effect on the oil temperature response (lowest curve). Apparently the boiler start up delay cannot be chosen on the grounds of an optimal oil temperature response.

In Fig. 8 evaporator water flows calculated for the three different time delays of boiler start up are shown. For a delay of 2 min (' $t=2$ ') steady-state conditions are re-established quickly but a high peak in water velocity is also observed. In the case $t=4 \min ($ ' $t=4$ ') there is less overshoot but we have a much larger time response of the flow. A boiler start up delay of $6 \mathrm{~min}$ ( $t=6$ ') might give problems. As the water flow is almost decreased to zero, there is no water head left in the condensate pipe. In this situation there is the risk of water flow reversal, resulting in water flow from evaporator to condensor. In fact the system has then changed to operate like a counter-current thermosyphon. Although the actual impact cannot be assessed exactly it is preferred to avoid this condition.

\section{CONCLUSIONS}

A model based on first principles has been developed for a two-phase co-current thermosyphon. The transient behavior of the system after a perturbation in steady-state operation is investigated. Density ratio vapor-liquid, dimensionless friction coefficient and water column length determine dynamic system characteristics such as response time, damping and oscillation frequency, respectively. Response time decreases with increasing vapor-liquid ratio. Relevant

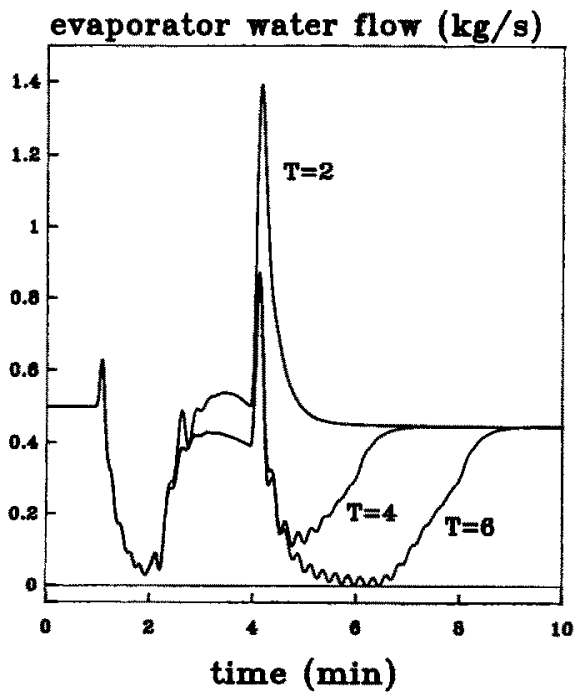

FIG. 8. Evaporator water flows at three different cases after drop of a new batch of oil. for the damping of the thermosyphon is that the pressure drop in the condensate flow is sufficiently high. The period of free oscillation is proportional to the square root of the liquid column length and equal to the period of oscillation of a liquid-filled open U-tube times a coefficient. The coefficient is in the range 1 1.4 and depends on the operating temperature. The results on the period of free oscillation are confirmed by experiments carried out earlier by Leidenfrost and Modrei [21]. In the case of the application of a thermosyphon for the batchwise heating of trays of oil, it follows that there exists an optimal boiler start up delay. If the delay is too small the water flow reaches high peak values. A long time delay may result in unstable flow situations.

The control volume approach provides a powerful tool to describe the overall performance of the thermosyphon with a limited number of variables. The predictive capacity of the model can be enhanced by improved representations of the two-phase flow in the evaporator region and the heat transfer in the condensor.

Acknowledgements-This research was supported by Unilever Research and Engineering. The authors express their appreciation for the comments from Dr G. van Duijn of O.P.A.U. (Unilever) and from Prof.dr.ir. J. J. H. Brouwers of the University of Twente.

\section{REFERENCES}

1. H. Cohen and F.J. Bayley, Heat transter problems of liquid cooled gas-turbine blades, Proc. Inst. Mech. Engrs 169, $1063-1080$ (1955).

2. E. L. Long, The long thermopile, Proc. Permafrost Int. Conf., pp. 487-491 (1963).

3. Y. Wakiyama, K. Harada, S. Inoue, J. Fujita and H. Suematsu, Heat transfer characteristics of a gas-to-gas heat exchanger using heat pipes, Heat Transfer Jpn. Res. 7, 23-39 (1978).

4. B. S. Larkin, An experimental study of the two-phase thermosyphon tube, CSME Trans. EIC 14, 1-8 (1971).

5. M. Cannviello, C. Casarosa, E. Latrofa, L. Martorano and F. Reale, Gravity heat pipes as geothermal convectors. In Advances in Heat Pipe Technology (Edited by D. A. Reay), pp. 759-766. Pergamon Press, Oxford (1982).

6. H. Imura et al., Heat transfer in two phase closed type thermosyphons, Heat Transfer Jpn. Res. 8, 41-53 (1979).

7. A. I. Strel'tsov, Theoretical and experimental investigation of optimal filling for heat pipes, Heat TransferSoviet Res. 7, 23-27 (1975)

8. F. Dobran, Steady-state characteristics and stability thresholds of a closed two-phase thermosyphon, Int. $J$. Heat Mass Transfer 28, 949-957 (1985).

9. J. G. Reed, Analytical modelling of two phase closed thermosyphon, Ph.D. Thesis, Department of Mech. Engng, Univ * Berkeley, CA (1985).

10. J. E. Hart, New analysis of the closed loop thermosyphon, Int. J. Heat Mass Transfer 27, 125-136 (1984).

11. M. Sen, E. Ramos and C. Trevino, The toroidal thermosyphon with known heat fux, Int. J. Heat Mass Transfer 28, $219-233$ (1985).

12. B. J. Huang and R. Zelaya, Heat transfer behavior of a rectangular thermosyphon loop, J. Heat Transfer 110, 487-493 (1988).

13. Y. Zvirin. Instability associated with the onset of motion 
in a thermosyphon. Int. J. Heat Mass Transfer 28, 2105 $2111(1985)$.

14. G. A. Hughmark, Designing thermosiphon reboilers, Chem. Engng Prog. 57, 43 61 (1961).

15. J. R. Flair, Vaporizer and reboiler design, Chem. Engng 8, 119-124 (1963).

16. K. P. Hallinan and R. Viskanta, Heat transfer from a vertical tube bundle under natural circulation conditions, Int. J. Heat Fluid Flow 6, 256-264 (1985).

17. T. W. McDonald, K. S. Hwang and R. Diciccio, Thermosiphon loop performance characteristics : part 1. Experimental study, ASHRAE Trans. 83, 250-259 (1977).

18. A. F. M. Ali and T. W. McDonald, Thermosiphon loop performance characteristics: part 2. Simulation program, ASHRAE Trans. 83, 260278 (1977).

19. T. W. McDonald and A. F. M. Ali, Thermosiphon loop performance characteristics: part 3. Simulated performance, ASHRAE Trans. 83, 279-287 (1977).

20. T. W. McDonald and S. Sampath, The bidirectional coil loop thermosiphon heat exchanger, ASHRAE Trans. 86, $37-47$ (1980).

21. W. Leidenfrost and P. Modrei, Flow conditions and heat transfer in a two-phase closed loop thermosyphon, ASME FED 61, 185-192 (1987)

22. C. C. J. Vincent, Steady-state and transient analysis of a co-current thermosyphon. M.Sc. Thesis, Department of Mech. Engng, University of Twente, Holland (1990).

23. R. B. Bird, W. E. Stewart and E. N. Lightfoot, Transport Phenomena, Chap. 15, pp. 229-231. Wiley, New York (1960)

24. R. Greif, Natural circulation loops, ASME J. Hea Transfer 110, 1243-1258 (1988).

\section{ETUDE DE LA PERFORMANCE GLOBALE VARIABLE D'UN THERMOSIPHON INDUSTRIEL DIPHASIQUE FERME}

Résumé- Un thermosiphon fermé diphasique est étudié pour dégager la performance dans une opération variable. L'approche par volume de contrôle est la base d'une analyse globale décrivant le mouvement des phases vapeur et liquide du système thermosiphon par des équations monodimensionnelles. Les forces cisaillantes interfaciales sont négligées. Les coefficients de transfert thermique sont hasés sur des formules empiriques. On trouve que le rapport de densité vapeur-liquide, le coefficient adimensionnel de frottement et la longueur de colonne d'eau déterminent les caractéristiques dynamiques variables telles que temps de réponse, amortissement et fréquence d'oscillation.

\section{UNTERSUCHUNG DES TRANSIENTEN GESAMTVERHALTENS EINES INDUSTRIELLEN ZWEIPHASEN-THERMOSYPHONS IN SCHLEIFENANORDNUNG}

Zusammenfassung-Ein Zweiphasen-Thermosyphon, der als geschlossene Schleife ausgeführt ist, wird im Hinblick auf sein Verhalten bei transientem Betrieb untersucht. Die Kontrollvolumina-Methode wird zur globalen Beschreibung der Bewegung von flüssiger und Gasphase in dem Thermosyphon-System durch eindimensionale Gleichungen angewendet. Schubkräfte zwischen den Phasen werden vernachlässigt, da nur gleichgerichtete Strömung der beiden Phasen auftritt. Die verwendeten Wärmeübergangskoeffizienten beruhen auf empirischen Beziehungen. Die Untersuchung zeigt, daß das Verhältnis von Dampf-zu Flüssigkeitsdichte, der dimensionslose Widerstandsbeiwert und die Länge der Wassersäule das dynamische Gesamtverhalten bestimmen. Dies betrifft beispielsweise die Antwortzeiten, das Dämpfungsverhalten und die Oszillationsfrequenz.

\section{ИССЛЕДОВАНИЕ ОБЩИХ ПЕРЕХОДНЫХ ХАРАКТЕРИСТИК ПРОМЫШЛЕННОГО ДВУХФАЗНОГО ТЕРМОСИФОНА С ЗАМКНУТЫМ КОНТУРОМ}

\footnotetext{
Аннотаиня-Исследуются характеристики двухфазного термосифона с замкнутым контуром в переходном режиме. Для анализа движения парообразной и жидкой фазы в термосифоне использовался метод контрольных объемов. Поскольку присутствовали только спутные потоки, напряжение сдвига на границе раздела не учитывалось. Коэффициенты теплопереноса определялись из эмпирических соотношений. Найдено, что отношение плотностей пара и жидкости, безразмерный коэффициент трения и дґина водяного столба определяют соответственно такие общие переходные характеристики, как время отклика, а также затухание и частоту колебаний.
} 